\title{
Reseña bibliográfica de: Luna, M. (2018). Telefonistas. Las obreras torturadas durante el primer gobierno de Perón. Buenos Aires: Ediciones ryr. 200 pp.
}

Palabras clave: Peronismo - Obreras - Telefonistas - Torturas

Keywords: Peronism - Female Workers - Telephone Operators - Tortures

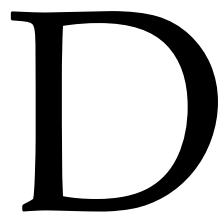
esde el momento de su gestación, y a lo largo de las décadas siguientes, el peronismo concitó la atención de los estudiosos sociales. Durante los años contemporáneos y posteriores a las dos presidencias de Perón se construyeron relatos en vistas a explicar los orígenes y las características particulares de este movimiento político. Numerosos científicos sociales en general, e historiadores en particular, estudiaron y expusieron un gran número de aspectos, contando entre ellos la trayectoria de Perón, los vínculos de aquél y del partido con la Iglesia, con el Ejército, con los empresarios, con los terratenientes, y con los sindicatos, las relaciones con el movimiento obrero en general y con la vieja guardia sindical en particular, la innovadora legislación laboral y la política económica.

Telefonistas de Marcial Luna constituye un intento por adentrarse en un universo poco explorado de esta época de la historia argentina: la represión y la tortura a obreras durante la primera presidencia de Perón. Y la apuesta va aún más allá: su autor no se remite a simplemente referir el conflicto particular de las telefónicas en 1949, sino que lo enmarca dentro de un contexto estructural trazado por Perón. A estos efectos, Luna repasa la legislación delineada por aquel gobierno, fundamentalmente la reforma constitucional de 1949, y las concesiones hacia sectores de la policía, definiendo el entorno legal para aquellas respuestas estatales a la huelga.

La Introducción de Marina Kabat que prologa la obra cumple un triple objetivo: contextualizador, historiográfico y bibliográfico.

En primer lugar, Kabat expone algunos aspectos del gobierno militar de 1943-1946, y de las dos presidencias de Perón. Prima allí la caracterización del vínculo entre Perón y el movimiento obrero: Kabat entiende que, tras una primera fase de acercamiento y concesiones entre 1943 y principios de 1946, los subsiguientes años estuvieron caracterizados por los intentos del presidente de cooptar al movimiento obrero y lograr su subordinación.

En segundo lugar, advierte algunas falencias historiográficas en torno al peronismo y su relación con el movimiento obrero. Tras constatar que Luna no trabaja con archivos secretos (tal como ella hiciera en PerónLeaks. Una re-lectura del peronismo a partir de sus documentos secretos), sino con materiales disponibles, argumenta la existencia de un defecto referido a silencios y omisiones en ese aspecto.

Anuario de la Escuela de Historia Virtual - Año 11 - N 17 - 2020: pp. 162-165. ISSN: 1853-7049. 1853-7049. http://revistas.unc.edu.ar/index.php/anuariohistoria 
Finalmente, ofrece bibliografía, filmografía e infografía relacionadas a la temática. Por un lado, libros y películas que abordan la vinculación entre el peronismo y el movimiento obrero y, por otro, ciertas obras que profundizan temas dentro de la misma constelación de saberes, como por ejemplo la violación de los derechos humanos y el trabajo femenino.

La obra de Luna consta de ocho capítulos. El primero se titula El comienzo de la historia. El autor expone la necesidad de analizar el contexto social y político de la década del cuarenta, la relación que construyeron Perón y los sindicatos, las causas e implicancias de la nacionalización de las empresas telefónicas, la cruzada estatal anticomunista en Argentina, y, fundamentalmente, el contexto de la reforma constitucional en 1949, en donde no se incluyó el derecho a huelga.

Para ello, describe en primer lugar la historia de las compañías telefónicas en Argentina, reconstruyendo el proceso que abarca la instalación de firmas extranjeras en el país hacia el último cuarto del siglo XIX, las variadas fusiones de capital en las décadas siguientes, y la adquisición de Unión Telefónica en 1946 por parte del Estado nacional.

El segundo capítulo, Dar para controlar, constituye un acercamiento a la construcción del vínculo entre Perón y el movimiento obrero organizado entre 1943 y 1946. Desde que el Departamento Nacional del Trabajo, con Perón como titular, fue convertido en la Secretaría de Trabajo y Previsión (STyP), el autor sostiene que Perón emprendería la doble estrategia de responder ante ciertas demandas obreras $\mathrm{y}$, al mismo tiempo, fomentar la canalización de los conflictos entre capital y trabajo por medio de la STyP.

El tercer capítulo, El otro Perón, parte de la premisa según la cual "Perón construyó alianzas y las mantuvo en tanto y en cuanto sirvieron a sus objetivos" (p. 65). A la luz de esta consideración, Luna muestra que Perón no dudó en recurrir a la represión, el encarcelamiento, la deportación y la destitución de los sindicalistas que obstruían sus intentos de "estatización" (p. 68) gremial. Pero añade, también, que se valió de la CGT para intervenir sindicatos y federaciones que no acataran sus disposiciones. Finalmente, expone cómo los diputados peronistas se posicionaron favorablemente de cara a este proceso de centralización de los sindicatos.

En el cuarto capítulo, Nacionalizaciones, el eje temático vira: el enfoque está puesto en la descripción del proceso de nacionalización de la Unión Telefónica, donde trabajaban las obreras que serían torturadas. En 1946, y tras planes gestados durante los años 1943 y 1944 bajo el gobierno del GOU, el Estado nacional adquirió gran parte del paquete accionario: el 19 de noviembre de 1946 se fundó la Empresa Mixta Telefónica Argentina (EMTA). Luego de dos años de magro desarrollo, el gobierno de Perón decidió concretar su nacionalización definitiva, en 1948.

En el quinto capítulo, Las huelgas, el autor argumenta que las respuestas del gobierno peronista a los paros sindicales tomaron un cariz particular. La estrategia estatal se basó cada vez más en un doble juego de represión versus concesión de mejoras, desprestigiando el accionar obrero y exaltando la mediación del Estado. Posteriormente, Luna aborda la reforma constitucional y un asunto en particular: la omisión del derecho 
a huelga. Enfatiza allí el contraste entre los diputados justicialistas de extracción sindicalista, defensores de esta exclusión, y las bases obreras que peticionaron para que se incluyera. Por último, realiza algunas referencias a la crisis económica que vivió el país desde 1949, completando el marco en el cual los trabajadores vieron decaer la posibilidad de negociar sus salarios.

El sexto capítulo, Teléfonos rojos, constituye la parte central de la obra. Allí Luna describe las protestas que las telefonistas llevaron a cabo durante los primeros meses de 1949, reclamando libertad sindical, elecciones y democracia, y una jornada laboral de seis horas por trabajo insalubre. El autor repasa los testimonios de las obreras, que relatan cómo el día 1 de abril fueron trasladadas por la policía federal a la Sección Especial de Investigaciones, luego de que sus domicilios fuesen ilegalmente requisados. Allí, fueron objeto de humillaciones y de torturas con picana eléctrica.

Las obreras, luego de infructuosos intentos de atravesar la vía judicial con sus denuncias, apelaron a la Cámara de Diputados. En 1949, los congresistas Reynaldo Pastor y Raúl Uranga presentaron proyectos con pedido de investigación. Sin embargo, ninguno obtuvo resultados. Para Luna, un elemento de relevancia -expresado en el título del capítulo- es la reiterada acusación con la que se señalara a las obreras "por ser comunistas". A su entender, lo fueran o no, el gobierno nacional utilizó esta justificación para avalar la represión de la policía federal.

En el séptimo capítulo, Reverberaciones, Luna expone que la versión de la prensa sobre los hechos fue el eco de la versión oficial: se llevaba a cabo una lucha contra elementos comunistas y peligrosos. Asimismo, el Estado dio una respuesta parcial a ciertos reclamos telefónicos que se produjeron tras los hechos de abril. No hubo, resalta Luna, condenas judiciales para políticos, ni para policías.

Cierra el libro el octavo capítulo, Desenlaces, donde Luna procura reunir la argumentación esbozada a lo largo de la obra y establecer algunas conclusiones. En vistas a entender por qué, efectivamente, se produjeron secuestros y torturas en un gobierno fruto del voto popular, el autor considera que es preciso aunar, dentro del relato, una serie de elementos: el Golpe de 1943, la progresiva cooptación de los sindicatos, la estatización de las empresas de servicios, el poder concentrado en la Sección Especial de policía (dependiente del ejecutivo nacional) y la consecuente represión con la que se castigó a los disidentes.

Este libro adquiere una importancia singular en la medida en que permite examinar costados menos atendidos del primer peronismo. Desde luego, a lo largo del libro Luna habla desde una marcada posición ideológica, y no intenta ocultarla. En sus páginas, deja entrever un posicionamiento político de izquierda y una defensa de los sectores trabajadores frente al avasallamiento patronal y estatal. Hay, de hecho, un interés político puntual en este libro, que guía los intentos de Luna por recuperar este episodio de tortura estatal a obreras para construir una memoria más completa. 
Se trata, por otro lado, de una obra breve en la que quizás abunden las citas textuales (por ejemplo, de documentos estatales) y los testimonios de ciertos protagonistas (sobre todo de algunas obreras torturadas o de algunos diputados).

Es necesario apuntar que, a partir de la segunda mitad de la década del ochenta, y al calor de la transición democrática argentina, comenzó a perfilarse en torno al peronismo cierto "Sentido Común Historiográfico". Esta normalización en los estudios históricos, de claro corte socialdemócrata y evolucionista, enfatizó la tarea integradora del peronismo frente a ciertos colectivos e invisibilizó sus costados totalitarios (Acha y Quiroga, 2009). Pues bien, investigaciones como la que Luna plasma en este trabajo contribuyen a deconstruir esa normalización historiográfica y a indagar respecto de ciertos costados totalitarios, represivos y no integradores de las dos primeras presidencias de Perón.

En conclusión, la intención de claridad y precisión en esta crítica y la intención de descubrir algunos aspectos, temáticas y cuestiones desatendidas o silenciadas durante largo tiempo permiten romper el cerco y abrir el juego a la construcción de una comprensión multiaxial sobre el peronismo de las décadas del cuarenta y del cincuenta.

\section{Referencias bibliográficas}

Acha, O. y Quiroga, N. (2009). La normalización del primer peronismo en la historiografía reciente. Estudios Interdisciplinarios de América Latina y el Caribe, 20 (1), 1-28. Disponible en: http://www.peronlibros.com.ar/sites/default/files/pdfs/achaquiroga.pdf [Consultado el 14 de febrero de 2020]

\section{Luciano Omar Oneto}

Universidad Nacional de Córdoba oneto.luciano@hotmail.com

Para citar esta reseña:

Oneto, Luciano Omar (2020): Reseña bibliográfica de: “Luna, M. (2018). Telefonistas. Las obreras torturadas durante el primer gobierno de Perón. Buenos Aires: Ediciones ryr. 200 pp." Anuario de la Escuela de Historia Virtual 17, 162-165. 